\title{
SIEGFRIED KRACAUER, SOBRE LA AMISTAD, EDITORIAL LAS CUARENTA, BUENOS AIRES, 2019, 88 PÁGINAS, ISBN 978-9874936-05-9
}

\author{
SIEGFRIED KRACAUER, ON FRIENDSHIP, EDITORIAL LAS FORTY, \\ BUENOS AIRES, 2019, 88 PAGES, ISBN 978-987-4936-05-9
}

\author{
(iD) Chausovsky, Alexis Ariel ${ }^{1 *}$ \\ alexchaus@hotmail.com \\ ${ }^{1}$ Universidad Nacional de Entre Ríos, Argentina
}

*Correspondencia: Chausovsky, Alexis Ariel. Email: alexchaus@hotmail.com

Recibido: 21.04.21 | Aprobado: 29.04.21

\section{RESUMEN}

La última década ha brindado la oportunidad al público hispanoparlante de conocer la obra del crítico alemán Siegfried Kracauer (1889-1966). Poco a poco, sus textos han cobrado vigor y el conjunto de sus producciones, aun disperso en español, gana sitio en la producción científica y filosófica contemporánea. La luz que actualmente se echa sobre el pensamiento de Kracauer comienza a desplazarlo del lugar que le fuera asignado hasta hace unos años, donde se lo conocía principalmente como un pionero en la teoría del cine, aunque algo ingenuo superado.

Palabras clave: Amistad, editorial.

\section{ABSTRACT}

The last decade has given Spanish-speaking audiences the opportunity to learn about the work of the German critic Siegfried Kracauer (1889-1966). Little by little, his texts have gained vigor and the set of his productions, even scattered in Spanish, gains a place in contemporary scientific and philosophical production. The light that is currently thrown on Kracauer's thinking begins to displace him from the place that was assigned to him until a few years ago, where he was known mainly as a pioneer in film theory, although somewhat naive surpassed.

Keywords: Friendship, editorial. 


\section{SOBRE LA AMISTAD, EDITORIAL LAS CUARENTA}

El lanzamiento de sus textos trazados durante la República de Weimar, y fundamentalmente entre las décadas de 1920 y 1940, demuestra su peso como una de las figuras primordiales de la crítica cultural de la República de Weimar. Ejemplo de ello dan su libro sobre la novela policial, sus recensiones literarias, sus estudios sociológicos, sus análisis sobre arquitectura, así como las piezas que formaron parte sus célebres libros $E l$ ornamento de la masa o Los empleados -producto de una investigación de las capas medias berlinesas en 1929 para el Frankfurter Zeitung -, o bien su biografía social sobre Jacques Offenbach. A tales ediciones podemos añadir la salida de sus trabajos producidos durante el exilio estadounidense desde 1941 sobre cine y cultura de masas o su trabajo póstumo denominado Historia. Las últimas cosas antes de las últimas, e inclusive la reciente publicación de Calles de Berlin y una de sus novelas, Ginster.

Sobre la amistad contiene dos artículos tempranos de Kracauer, de los cuales despuntan temáticas y modos de abordaje de los problemas que cobrarán mayor espesor en su escritura subsiguiente. La pieza inicial data de 1918 y fue publicada en la revista Logos. Allí reconoce que hay palabras que "corren de boca en boca a través de centurias, sin que su contenido conceptual quede nunca perfilado de una manera clara y rigurosa ante nuestra mirada interna" (Kracauer, 2019: 19) y, por lo tanto, se dedica a definir el concepto de amistad y a trazar una taxonomía de diferentes tipos de relaciones suelen confundirse con él. No es este un procedimiento aislado en la pluma de Kracauer; basta echar una mirada a sus célebres escritos "Los que esperan" o "Aburrimiento", de 1922 y 1924, respectivamente, para dar con él. La primera forma de relación que se expone es aquella de la camaradería, que reúne a las personas en una acción común con una meta planteada desde el exterior, frente a la cual son iguales. Nada vincula a las personas fuera de los límites del propósito compartido en tiempos y espacios específicos. Inmediatamente buscaríamos ejemplificar este tipo de relación con los nexos entre los compañeros de profesión, pero Kracauer indica que estos se denominan colegas.

La relación entre colegas, segunda en la clasificación de nuestro autor, lleva a entrever que la tarea en común deja una huella intensa en la conciencia y en las fuerzas espirituales del individuo ligado a un tipo específico de comunidad en un campo laboral duradero. Hay un grado de excitación común que en la agrupación sobrepasa los bordes de la mera camaradería. Sin embargo, aquí ya no estamos hablando de la igualdad de seres para concretar un objetivo colectivo; "el espíritu de casta que se genera gracias a cada profesión representa un medio vinculante entre los colegas" (Kracauer, 2019: 28). Simultáneamente puede haber una tendencia a la solidaridad entre miembros de una misma profesión y la búsqueda por sobresalir respecto de los demás. Ahora bien, de esta vinculación están segregadas las inclinaciones y los asuntos personales: los sueños, los recuerdos, los deseos, el amor.

La tercera forma de relación recorrida por Kracauer es la de los conocidos. Aquí ya no hay una meta o un asunto en su origen, sino que surge de una necesidad interior por ensanchar y proyectar con otros la multiplicidad propia de cada ser humano. Entre conocidos hay una distante proximidad que no implica una evolución en común en pos de un propósito expresado desde el exterior, sino que satisface en el trato directo e inmediato para el intercambio de pensamientos, ideas o el disfrute en el vaivén de una 
charla agradable. Claro que, más allá de la fluidez (término tan caro a Kracauer), el vínculo entre conocidos tiende a la estabilización en posiciones fijas. Camaradas, colegas y conocidos coinciden en lanzarse a condiciones supraindividuales que representan modos heterogéneos de comunicación (según necesidades más específicas o amplias).

Sin embargo, sostiene Kracauer, las personas que desean más formas de comunicación las procuran en una comunidad más vasta y expresan su anhelo de amor que suprima las distancias, ya sea en el amor sexual o en la amistad, que "tienen asida toda el alma de la persona" (Kracauer, 2019: 36). En las relaciones de amor se tiende a continuar una vida en común, más allá de las delimitaciones espaciales y temporales. La amistad implica abarcar todo el ser, en lo espiritual y lo corporal, de una persona, involucrando la conciencia del yo que se pone en común. Así, se funden fuerzas dispersas y la diversidad interior se encuentra en un flujo perpetuo que ensancha el yo. Por eso, la amistad "es la comunidad de convicciones y de ideales que se basa en un desarrollo conjunto de las posibilidades típicas de personas libres e independientes. Desplegarse en común sin perderse uno en el otro, donarse, para poseerse de manera ampliada, fundirse en una unidad y, sin embargo, mantenerse en una existencia separada para sí mismos: este es el secreto del vínculo" (Kracauer, 2019: 61). Con esta definición, Kracauer sienta una postura que se podrá proyectar en "La biografía como forma de arte de la nueva burguesía" de 1930, donde lanza sus invectivas hacia los individuos oficialmente rotulados, o hacia sus protestas contra la mecanización en "El viaje y el baile" de 1925 o el informe sobre Los empleados.

La segunda pieza del libro actuará como una continuación con leves modificaciones respecto de la primera. Nos encontramos ahora con un ensayo que sirve de homenaje en 1921 al rabino Nehemia Anton Nobel, personaje clave en la conformación de la Freie Jüdische Lehrhaus de Frankfurt, que será dirigida por Franz Rosenzweig y Martin Buber y representará una instancia clave del renacimiento judío en la ciudad (Jay, 2017). En esa institución ingresará Kracauer gracias a Leo Löwenthal (precisamente, una de las amistades que serán conservadas por nuestro autor en el decurso de los años subsiguientes).

Este escrito parte directamente de las reflexiones sobre la noción de amistad, describiendo específicamente las fases que la pueblan en su interior. Por lo tanto, será el diálogo el estímulo principal que advierte Kracauer en la amistad, realzando el desencadenamiento de sucesiones de pensamientos o emociones que en él se trazan. Con el diálogo se estrechan los vínculos, se establecen las condiciones para una comunidad de convicciones y afloran los estratos más hondos del alma. El diálogo se combina con la segunda instancia, que se representa en los períodos de separación. En la distancia se produce una correspondencia entre los amigos; cada cual progresa por su parte, incluso evocándose mutuamente. Desde ya que aquí tenemos un punto relevante para diferenciar a los amigos de los amantes; mientras que en los primeros la presencia no es una exigencia absoluta, en los segundos requiere un cumplimiento de la vida en común. Por eso, "toda verdadera amistad es elástica y consiente en una medida considerable estos extrañamientos que se fundamentan en su naturaleza" (Kracauer, 2019: 71). 
Ahora bien, Kracauer distingue la amistad ideal o en su plenitud de la amistad intermedia, en la cual florecen solamente aspectos parciales de las almas. Las amistades intermedias conforman un estadio preliminar de la amistad ideal, pues no producen el deseo de una comunidad y de una expresión ilimitada del yo. La amistad creadora, la amistad de día festivo, las relaciones de discípulo y maestro o la "amistad del corazón" son pasibles de ser examinadas a partir de allí. En definitiva, la común entrega de la totalidad de las almas, de seres con conciencia de su personalidad en toda su profundidad, será la que defina la amistad ideal, en la cual el yo se expande a nuevas posibilidades.

No se puede concluir la presente reseña sin decir que la Introducción del libro, a cargo de Francesc J. Hernández y Benno Herzog (quienes también se dedicaron a la traducción y a las notas), resulta esclarecedora. Allí detectan que el interés del volumen se fija en una filosofía o teoría de la amistad, en su valor para la comprensión de la denominada Teoría Crítica -de la cual Kracauer será uno de sus representantes- y las noticas biográficas del autor y de los integrantes de la Escuela de Frankfurt. En el primer punto se demuestra la incidencia de Simmel y Scheler en el pensamiento de Kracauer, quien aborda un problema filosófico ya presente en Platón, Aristóteles, Cicerón, Montaigne o el romanticismo alemán. En el segundo punto, relumbra el aporte de Kracauer a partir del mayor alcance que tienen Los empleados o El ornamento de la masa, luego de la segunda mitad del siglo XX, así como sus posibles articulaciones con Teoría del cine o su póstumo libro sobre historia. En el tercer punto, brilla la importancia que tendrán las relaciones de amistad con Lówenthal y Theodor W. Adorno. Especialmente, se conjetura que los artículos aquí reunidos se proyectan directamente sobre la íntima y tensa ligazón que ha unido a los amigos Adorno y Kracauer (Teddie y Friedel, como se dirán entre ellos). Por nuestra parte, agregamos un cuarto punto, que se refiere a la articulación de los textos aquí compilados con el estudio de los modos de escritura de este Kracauer, quien se inclinará aquí a ensayos breves y con un tono cercano a su libro sobre la novela policial, pero anticipa la sagacidad de sus viñetas sobre la cultura de masas (especialmente, las salas de teatro y cine, el circo o diversos films), el rigor de sus comentarios sobre arquitectura o la teoría del cine.

\section{REFERENCIAS BIBLIOGRÁFICAS}

M. Jay (2017), Exilios permanentes, El cuenco de plata, Buenos Aires.

Kracauer (2019), Sobre la amistad, Las cuarenta, Buenos Aires. 2019, 88 páginas. Puriq, 3(4), 645-648. https://doi.org/10.37073/puriq.3.4.189 